to infer that dysmenorrhœa depends upon some obstruction to the free passage of the menses, and this can only be ascertained by probing the womb. While giving to Sir James Simpson all credit for having taught us how to sound the womb, and the value of the information to be thus obtained, I agree with Dr. Marion Sims that it is better to use as little as possible the instrument sold as his; and if I have stated that I consider it unjustifiable to slit the neck of the womb when the uterine sound could be passed without difficulty, my object was to express a means of measurement that everybody could understand-a precaution rendered necessary by the fact, that those who recommend the frequent performance of this operation omit to state what they consider to be the normal width of the cervical canal.

When a resistant probe is required, I prefer Chassaignac's uterine sound, which is shorter than Simpson's, and only slightly curved at its extremity ; but for ordinary use there is nothing better than the well-known wax bougies: they seem to have a peculiar aptitude to pass through the strictured canals, and I have often been able to pass one when $I$ have failed with the uterine sound, the calibre of the two instruments being the same. Another great advantage of using wax bougies is, that it is difficult to do harm with them. If they cannot pass the stricture, they bend and are expelled by the womb, whereas the uterine sound often canses great pain and loss of blood, sometimes inflames the womb or the surrounding tissues, and has been repeatedly known to perforate the womb when used by inexperienced hands. No one should introduce a bougie, and still less a metallic sound, in to the womb, without previously ascertaining its shape and position, so as to know what curve it may be useful to give the probe, and in what direction to introduce it. It must be particularly ascertained, by means of the finger in the vagina and sometimes in the rectum, whether the body of the womb is not fiexed upon the cervix; for those who do not detect this condition will of course find great difficulty in passing the sound, or may not be able to do so, and may subject their patients to useless treatment by sponge tents, as I have seen in several instances. It will be obvious that in cases of this kind the wax bougies are of much safer use than the rigid metal rod, and if the wax bougie be carefully brought away, it will, to a certain extent, bear the impression of the curve in which it has been moulded.

With regard to the dangers attending the division of the cervix, they will depend upon the extent to which the division is carried. If the cervix has been divided right and left, down to its vaginal attachments, one cannot be too careful of the patient for the following days ; but this is very seldom required. In the majority of cases in which one or two longitudinal incisions, to the depth of two or three lines, are made inside the cervical canal, particularly when the os internum is not divided, or when the os externum and adjacent tissues are thoroughly divided to the extent of three-quarters of an inch, it is quite unnecessary to subject the patient to the fuss and expense of a skilled nurse, or to enforce silence, and keep "the patient in bed for three weeks, as if some fearful operation had been performed. Common sense will teach the happy medium between foolhardiness and a ridiculons amount of precaution, and I am desirous of saying this, for I have myself exaggerated the dangers of the operation in my "Handbook of Uterine Therapentics."

Surgical skill is the highest kind of skilled labour, and the surgeon has the right to value his work as he likes. The public need not employ him if they think he overestimates his skill; nevertheless there is a tacit understanding with respect to the fees that should be asked for various operations, and surely there should be a similar agreement respecting the fee for division of the cervix. At present some practitioners take five or ten guineas, which seems to me too moderate a fee, while others ask a hundred or a hundred and twenty five guineas, which is obviously exorbitant, considering that no more is asked for ovariotomy, or for amputation of the thigh.

Grosvenor-street, Grosvenor-square, Jan. 1867.

Scurvy. - We find by returns received from Liverpool, and collected by Mr. Reginald Harrison, Lecturer on Anatomy at the Liverpool School of Medicine, that the number of cases admitted into hospitals in that town during the past year exceeds by fifteen thoze entered on the books of the Dreadnought during the corresponding period. The Royal Infirmary furnishes a list of 22 , the Northern Hospital of 35, and the Southern Hospital of 59 cases, out of which 2 deaths have occurred at the Southern Hospital and 1 at the Royal Infirmary.
REMOVAL OF A METALLIC PENCIL-CASE FROM THE BLADDER OF A WOMAN SIX DAYS AFTER ITS INTRODUCTION.

\author{
WITH INTRODUCTORY CLINICAL REMARKS.
}

BY THOMAS NUNNELEY, F.R.C.S., SURGEON TO THB LEEDS GENERAI INEIKMARY.

GentLemer,-Following the course which, as a rule, I have adopted in my clinical lectures, of calling your attention to those cases under my care in our General Infirmary which are of great interest and importance, whether from the rarity of the affection, the importance of the disease, the obscurity of its diagnosis, the difficulty of its treatment, its being a typical illustra. tion of a particular affection, its being a connecting link between disorders at first sight not presenting much in commor with each other-as the very varied forms of erysipeloid affections, which some of you will recollect I have more than once brought under your notice, with the view of proving to you how varied and, apparently, isolated complaints, having individual names and histories, are really but varied forms of this protean malady, owning a common origin and interchangeable, each form capable of inducing the other forms ; or even of complaints of more frequent occurrence and of more easy management, but of which the importance of knowing them well is in your future career certain to be great; - I shall call your attention to the case of a woman whom many of you have lately seen in No. 10 ward. Though it is certain none of you will frequently be called upon to treat such a case, and even probable that many of you may not meet with a single one, yet it is of great importance when it does occur that you should understand it, and of interest that you should be prepared to manage it with skill and decision, or the consequence may be very serious to your patient.

This, as $I$ understand the term, is the true meaning and value of "clinical lecture," rather than the delivery of an essay on the principles and practice of surgery. These, I hold, should rather be learned in the course on the principles and practice of surgery, or by private study of those excellent books and dictionaries on surgical science which it is open to all to obtain; or, better still, by a careful reading of original essays by writers who have made the particular subject their especial study. Bedside lectures, I think, are more appropriately devoted to pointing out from the patient then directly under observation the meaning and value of symptoms there presented to us, the inferences which are to be deduced from them, the treatment which is most applicable, and the reasons why one remedy or one procedure is adopted in that particular case rather than another; for though we may follow, in all cases of the same disease, the same general outline of treat. ment, yet we shall find in each case, whether arising from constitution, age, or idiosyncrasy, the stage of the complaint, the particular part where it happens to be located, or any other cause-and there may be many, - that great and important modifications are needed. Now, the proper adaptation of these modifications is all-important, and, not unfrequently, makes all the difference between curing the patient, and, if not absolutely injuring him, at any rate not doing him any good. In fact, it is this knowledge, which experience and tact confer upon the well-grounded and thonghtful practitioner, which is so valuable to his patient, and which distinguishes the man of experience from the theorist and merely erudite man. This is nowhere to be so well acquired as at the bedside of patients under the guidance of those who are com. petent to the task. It makes no difference to the character of the lecture whether given in this theatre, at the school, away from the infirmary, or by the bedside of the patient. This place is merely chosen as a matter of great convenience, not only to the patient who is the immediate subject of the remarks, but also to you ; for symptoms, treatment, and results can all be more freely discussed away from him than they possibly can be in his anxious hearing.

You will therefore understand that I expect you all to have some acquaintance with the principles of surgery. It is my object to point out to you, as cases arise, how you may best apply these principles to the particular case which is the sub- 
ject of our observation. I may, and probably shall, from time to time, deviate from this plan by passing, when I consider it to be advantageous, from the individual case to some of the general rules and principles of surgery. Thus, when I think I can more strongly impress them upon your attention by showing how they have governed the management of the particular case to which they are applicable, I may use this as an illustration of their importance : as, for instance, when I come to speak, as I shall probably take an early opportunity of doing, upon that serious accident case which was yesterday admitted, where both femoral artery and vein, with the greater sphena nerve, were torn across, through a comparatively small external wound-so small, indeed, that I am told the surgeon who first saw the man did not consider the wound to be a dangerous one, yet in which $I$ had recourse to immediate amputation; and to that railway accident just admitted, where both legs have been cut off,-I may point out what kinds of accidents imperatively demand amputation of the injured limb.

Let us now proceed to the details of the case immediately before us.

On going to the infirmary a few Sundays ago I was told by the resident assistant that a woman had presented herself during the forenoon saying that she had a pencil-case in her bladder, though he hardly gave credit to her statement, as she had walked at least two miles. As I was expected to see some of the more urgent cases, he very properly detained her, though she was reluotant to remain, as she said she had not mentioned the matter to anyone, and she was particularly anxious that her husband should not become aware of it, which, if she were long away from home, being Sunday, he might do, as he would be searching for her, and if found at the hospital, would require to know the cause of her being there. I found her sitting in No. 10 ward, with a countenance of great anxiety, and evi dently in a state of considerable suffering. My notes say "She is a very stout, good-looking woman, forty-four years old ; has had seven children, the eldest of whom is twentythree and the youngest four years of age; she looks a strong and healthy woman ; she menstruated a fortnight ago, and is quite regular. She says that on last Tuesday night, six days ago, after she had got into bed (her husband also being there), as she had not for some time passed water very freely, and fancying something might be in the way, she pushed a Germansilver pencil-case into the passage to make room, when it slipped from her fingers and was lost. Since that time, though but the blades could not be opened sufficiently to embrace the case, though when they were shut they could be passed behind it and used as a lever.

Fearing to lacerate the mucous membrane of the bladder by the employment of much force, Thad the woman tied in the lithotomy position and put under chloroiorm. Weiss's urethra dilator was gradually and slowly used until the left forefinger could be passed into the bladder, when the pencil-case was readily felt to be in the position before mentioned. A very small narrow curette, well curved at the end, was now introduced beside the finger, and by this guided to the end of the case, which pressed upon the posterior surface of the bladder. The end of the case, placed between the finger and the curette, was then lifted up and at the same time drawn forwards, so as to bring it into a line with the urethra. By thus keeping up a good pressure upon the case it was securely held and drawn out of the bladder. Where the sharp hard point of the pencil had rested the mucous membrane was felt to be rough and somewhat ragged, as though ulcerated. A few drops of blood followed the removal of the dilator, which the stretching by it had caused. Subjoined is an accurate sketch of the exact size and form of the pencil-case, which measured nearly four inches and a half in length by a third of an inch in breadth. The projecting pencil-point was hard and sharp, as though recently cut. It was well for the woman that the opposite end of the slide, which carried a long steel pen, had not happened to be the one which projected, or it would certainly have penetrated through the bladder into the rectum. The pencil was probably the part held by the woman when she passed the case, and thus the last introduced into the bladder. The case was deeply stained with sulphur, but had not any earthy incrusta. tion upon it.

The patient was placed in bed, and ordered to have six grains of calomel with one grain of acetate of morphia immediately, and plenty of barley-water. She suffered great nausea from the chloroform, otherwise she expressed herself as much relieved. She recovered without any interruption. At first there was no incontinence of urine. This was scanty, highcoloured, and contained both blood and pus ; it was passed in quantities of about four ounces. She had a dose of calomel and opium for the first four or five nights, with an alkaline mixture containing some sulphate of magnesia. For diet she was allowed broth and farinaceous food. The urine gradually became more abundant, while the blood and pus diminished and disappeared. About the fourth day there was some in

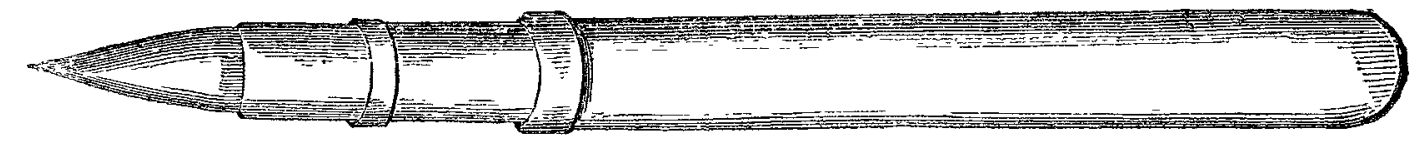

going about her household work, she has constantly suffered great pain, and has been unable to hold her water. At present there is much tenderness at the lower part of the abdomen." She was closely questioned as to whether she had ever prac. tised such a proceeding before, as her suspecting "something might be in the way" led me to suppose this might not be the first time of her using an impromptu dilator. However, she strenuously asserted this was the only time she had ever practised it. I had her taken into the operating room. On introducing my finger into the vagina, to ascertain if peradventure the case had been thrust up there, she immediately exclaimed, "Oh! it is not up there, but in the other place." I carried the finger far up the vagina, and pressed with the other hand on the lower part of the abdomen, when she complained of great pain; but I could not feel anything in the bladder, probably from the thick layer of fat. The urethra was capacious, and from it urine tinged with blood was constantly oozing, by which the external parts were excoriated. On introducing a curved sound, at first nothing could be felt except a strongly contracted bladder; but with a little care and time, a sharp, clear, metallic ring, audible over the whole room, was got; but so closely was the substance embraced by the walls of the bladder that it was some time before the noise was repeated, and only that the body, whatever it was, lay towards the right rather than the left, and not its size or shape, could be ascertained. Small straight urethral forceps were introduced, but could not be made to touch it, so closely was it embracer by the bladder. With an angular sound a more precise examination was made, and the pencil-case clearly ascertained to lie to the right side, and to extend directly from before backwards. I now passed a pair of curved forceps into the bladder, continence, which was never considerable, and in ten days passed away. She was so well that she was made an outpatient, with directions to show herself every three days; but she has only presented herself twice. All that she complained of when last seen was of being obliged to void her water at more frequent intervals than before the occurrence, which, if not already gone, in all probability will soon disappear; at any rate, the inconvenience is not sufficiently great to induce her to continue any treatment for it.

It is difficult to conjecture what was the precise motive or feeling which induced this woman to play such a trick upon herself. Queer things have been employed both by men and women for self-abuse, and several cases are on record where the substance employed has got into the bladder; but in women, I think, these will more commonly have been found in the vagina than in the bladder, and more commonly to have been used by younger persons than this one. Hysterical and unmarried lascivious girls have more frequently been the victims than older married persons. This woman knew perfectly well the exact place into which she had carried the pencil-case. She had had children enough to satisfy any moderate person, and had her husband beside her when it was done; it is, there fore, not improbable that her statement of fancying she could remove something which was in the way of her passing urine freely may be the true one. But it is often hard to penetrate into psychological motives, and as with us, in this instance, the practical matter of removing the foreign body was the consideration, we will pass by the impelling cause of the strange lodgment, and say a few words on its dislodgment.

The first thing to do was to be certain if such a body as a 
pencil-case, or anything else, were really in the bladder, for you must remember that those women who introduce such things are precisely those who are most likely to deceive themselves and us by asserting that they have done so when they have done nothing of the kind; and the second is, having satisfied ourselves of the presence of the substance, to remove it with the least possible injury to the parts involved.

With regard to the first question, I should have almost supposed there would not have been any great difficulty, with a finger in the rectum or vagina, and a hand on the body, in detecting a hard, unyielding substance of the length and in the position of this pencil-case; but such was not so. The pressure occasioned considerable pain, but did not reveal the presence of it. The statement of the woman after having introduced it, that since then there had been continual incontinence of urine, and her suffering countenance, would be worth something in our diagnosis, which the constant dribbling of bloody urine went far to confirm. This the introduction of a sound converted into a certainty, for it demonstrated not only the presence of some foreign substance, but that it was a metallic body; for though some tact and some little patience were required before it was struck with the sound, when it was touched, the sharp clear ring, so loud that it could have been distinctly heard for at least a distance of twenty yards, could have been obtained only from two hard metals being struck against each other. It therefore not only proved the presence of a foreign body, but that this was a hard metal. It did more, for it showed us the position, shape, and general direction of it, which the introduction of the finger into the bladder carried still further, for it told us that the sharp dangerous point of the pencil pressed backwards, and thus gave us the desired information of the direction in which the removing force should be directed so as to avoid laceration of the already inflamed and softened lining mucous membrane, so easily lacerable, and so troublesome to cure after it has been injured. Some of you may not improbably ask me why I did not use the endoscope. I will tell you why $\mathrm{T}$ did not do so. In the first place, because I never employ a complicated instrument, which is difficult of application, when it will not answer any purpose better than a more simple one; and in this case I do not think even the most successful application of it would have given any more information than the finger and the sound did, both of which would have had to be employed as they were, even had the endoscope been used. In the next place, it would have been very difficult, if not dangerous of application, for the bladder was empty and inflamed, and $I$ do not know how the female bladder could be even moderately distended by injecting water, unless the urethra be distended by an enormous instrument; and in the third, so far as I have seen, very little or no practical information has been revealed by the endoscope, while I have more than once seen very considerable suffering inflicted by a persistent use of it. That the time may come when the instrument, by modification in its form, and experience in its proper application, may prove a valuable aid to diagnosis, is, I fully believe, probable ; that at present I have seen any advantage in its introduction into the bladder I am not prepared to admit.

As for the removal of the pencil-case from the bladder, I think that the best means were adopted to prevent any further injury to the nucous membrane. When it was once placed between the finger and small curved scoop there was not the least difficulty in lifting it up so as to dislodge the point from the membrane in which it was imbedded, and drawing it forward. When this was done, very little effort was required to bring it out of the urethra, for the bladder immediately contracted, and so materially facilitated the extraction of it. There is one point which I should recommend for your careful consideration, should such a case be presented to you-namely, the age and condition of the person, and whether you may venture to dilate the urethra to the extent and with the rapidity adopted in this instance. If the patient had been young, unmarried, with a small, rigid urethra, I should not have done so, fearing permanent incontinence of urine might have resulted, as has so frequently followed the extraction of calculi from the female bladder by forcibly pulling them through the urethra, rather than by dividing some of its mus. cular fibres. I then should have dilated the urethra more gradually, by introducing successive portions, of graduated thickness, of the laminaria digitata. But as in this woman the urethra was very large and very relaxed, yielding with great facility to very little distending force, I thought there would be very little fear of its not again contracting without any paralysis of the constricting fibres. The result showed the opinion was well tounded.

\author{
ON
}

\section{AUSCULTATION BY THE AID OF MUSICAL VIBRATIONS.}

BY WILLIAM H. STONE, F.R.C.P., $\triangle N D$

MICHAET, GRABHAM, M.R.C.P.E.

IN the course of inquiries which I have for some years been led to make, as to the effect of playing wind instruments on the chest, both in a healthy and diseased condition, I have incidentally met with an application of musical vibration which may prove to have some diagnostic value. My friend, Dr. Grabham, of Madeira, has also been making similar ex. periments in a different form, and since his temporary return to England we have been examining the facts together. The subject is, we believe, of sufficient interest to be laid before the profession at an early period, while we hope to furnish farther details in a subsequent communication.

The method I have myself adopted consists simply in com. municating a musical impulse to the air in the bronchial passages, by forcibly inspiring through a tube, or pitch-pipe, containing a free reed. The note emitted is thus directly conveyed to the parts under observation, and we can easily feel its vibratory character in the posterior fauces and trachea when we sound the instrument ourselves. In this respect the inspiration note differs entirely from any that can be produced by expiration. The latter are mainly, if not entirely, forced outwards with the current of air, and excite little or no intrathoracic consonance. The same remark applies to the sounds heard with the ordinary voice in speaking. Vocal resonance is a somewhat complicated phenomenon. The vocal cords or rather membranes, when set in motion by the expelled current, not only originate a musical sound of variable pitch, timbre, and loudness, according to age, sex, and idiosyncrasy, but actually communicate vibrations sensible by touch to the neck and thorax. This is commonly called vocal thrill, or fremitus, and is with many voices quite inseparable from the purely musical vibrations.

But the note from a reed pipe, drawn into the chest by the act of inspiration, is entirely unaccompanied by any fremitus whatever ; thus giving the results of consonance in a form of complete purity.

$I$ have long been in the habit of requesting patients, whose knowledge of music enabled them to comply with my request, to intone, or articulate, on a single given note, by way of clearing the vocal resonance of extraneous and heterogeneous vibrations which commonly clash together in the inflections of speech; and I have observed that the indications are infinitely more distinct to the listener's ear. 'The same fact affects the voice of the intoning priest in large cathedrals, compared with that of an ordinary reader. This is an experiment which can easily, and I hope not irreverently, be tried any day at St. Paul's and Westminster; even in the most remote aisles and chapels, the chanted prayers come to the ear distinct and to be recognised; whereas the lessons, though read by the same voice, and that, virtute officii, a good voice, are reduced to a murmuring jargon of unintelligible sounds. Indeed, I have always attributed the practice of intoning more to experience, and, if I may use the phrase, to instinct, than to the traditional invention of chanting and Gregorian music by King Solomon, and their providential preservation since the first services of the Temple. But apart from ecclesiastical buildings, the same process may be heard in operation wherever the human voice has to be made audible to numerous assemblies. A good public speaker almost unconsciously slips from his conversational tone and inflected delivery, into a sharper pitch and a more perfect monotone. It is, perhaps, not irrelevant to cite, as an instance, the late Chancellor of the Exchequer; for there can hardly be any doubt that that distinguished orator owes much of the marvellous fascination which his speaking possesses to the gift of a fine baritone voice, and the musica attainment needed for its adaptation to various acoustic con ditions. The moment this consonance is attained, the voice begins to travel with greatly increased power; by the uniformity of its tone it can overpower incongruous noises, and it is not materially weakened by the interferences necessarily arising between echoes of the primary note and the utteranie 